\section{El odontólogo: actual pandemia y su legado}

\section{The dentist: current pandemic and its legacy}

\section{Sr. Editor.}

Como odontólogos, durante el trasegar de los tiempos, nos hemos visto enfrentamos a retos inimaginables que nos han permitido tomar decisiones acordes y razonables dentro del marco personal de cada profesional de la salud oral. La actual pandemia no ha sido la excepción, ésta, además, de habernos separado de nuestros pacientes en el ámbito clínico y de los examinados en lo forense, nos ha llenado de miedos al atender y al ser atendido.

En la actualidad y frente a la pandemia, la posición del odontólogo ha sido compleja porque se le ha excluido como parte del equipo de la salud en general, no ha sido visto como apoyo primordial de primera línea en salud sino como agente contaminante. Ello conlleva a que esta situación ha dejado al descubierto todas las falencias en nuestro sistema de salud y desdeño de los gobiernos con los profesionales de la odontología a quienes no se les tiene en cuenta y se les niega la ayuda estatal, aun sabiendo que gran parte de ellos, por ser profesionales independientes, son trabajadores que viven de sus ingresos que reciben diariamente, convirtiéndose además en un atropello por parte de las autoridades sanitarias territoriales, cuando se toman decisiones y políticas relacionadas con la atención en salud y programas de prevención; especialmente en situaciones como las vividas en la actualidad. Percibimos que las autoridades sanitarias solo piensan en los demás profesionales de la salud y nosotros somos los últimos en la cadena. ¿Será que un paciente positivo Covid o cualquier otro paciente no tiene derecho a una atención odontológica diferente a resolver su situación de extrema urgencia?

Somos profesionales de primera línea, por tanto, necesitamos ser visualizados dentro del personal de salud como una población de alto riesgo de contagio, particularmente porque la atención dental por sus características es una situación de alto riesgo para los profesionales odontólogos y los auxiliares en odontología o de salud oral, debido a que los procedimientos dentales producen gotas y aerosoles, potencialmente contaminados. Además, existe contacto estrecho entre el clínico, el paciente y/o examinado. Sin embargo, se deben tomar medidas de precaución antes, durante

\section{Carta al Editor}

\author{
Carmen Esther Orjuela Henao 1,a, Adriana Iveth Pérez \\ Castañeda ${ }^{2, b}$, Fanny Doris Reina Garzón ${ }^{3, c}$ \\ ${ }^{1}$ Instituto Nacional de Medicina Legal y Ciencias Forenses, \\ Bogotá, Colombia. \\ ${ }^{2}$ Instituto Nacional de Medicina Legal y Ciencias Forenses - \\ Seccional Boyacá, Tunja, Colombia. \\ ${ }^{3}$ Práctica privada, Tunja, Colombia \\ a Odontóloga Forense. Especialista en Docencia \\ Universitaria. \\ ${ }^{\mathrm{b}}$ Especialista en Odontología Forense. \\ ${ }^{c}$ Especialista en Endodoncia.
}

\section{Correspondencia:}

Carmen Esther Orjuela Henao: carmestorhe@gmail.com Carrera 1 D \# 11 - 01 Torre 7 Apartamento 504

Chía-Cundinamarca-Colombia

ORCID: 0000-0003-4603-9771

\section{Coautores:}

Adriana Iveth Pérez Castañeda: aperecas@gmail.com ORCID: 0000-0002-0373-7564

Fanny Doris Reina Garzón: fannyreina2000@yahoo.es ORCID: 0000-0003-3085-5192

\section{Conflicto de intereses: ninguno.}

Recibido: $11 / 08 / 20$

Aprobado: 19/08/20

Publicado: 16/11/20 
y después de la atención dental para reducir el riesgo de contagio entre el paciente y el personal de salud dental.

Consideramos que lo expresado anteriormente se debe, en parte, a la falta de solidaridad gremial que viene desde la formación del pregrado en cada una de las facultades universitarias. Es por ello, que se obtiene como resultado la falta de liderazgo como profesión que propicia el bienestar y una mejor calidad de vida. No tenemos en cuenta en algunos casos "la lealtad, la consideración, la solidaridad y el mutuo respeto entre los colegas son los factores esenciales o el fundamento de las relaciones entre los odontólogos" ". Lamentablemente, ante la primera oportunidad que tenemos de competir con nuestro colega no la desaprovechamos, somos destructores de nosotros mismos desconociendo que se trata de una falta a la ética por la competencia desleal.

Si bien los gobiernos no nos dan el lugar que nos pertenece, la pandemia si lo hace, somos una tendencia laboral en el sentido que nuestro trabajo no lo puede realizar una máquina, somos los únicos que podemos dar una verdadera solución al tan temido e incapacitante "dolor dental" 2 . Un dolor no se puede tratar desde la casa, por tanto, no se puede prescindir del ser humano para su atención. De igual manera, la atención odontológica forense no se puede realizar acudiendo a las herramientas de internet porque podemos caer en la frialdad de la atención cuando llega una persona con todo su dolor por la situación vivida y aún agravada por la pandemia. No es posible prescindir de la atención personalizada porque a través de videos o fotografías se pierden detalles o decisiones de tomas de muestras que pueden ser de tal importancia al emitir nuestra conclusión pericial, al punto que se puede cometer errores. Así como en la clínica, no es posible que otro profesional de la salud realice nuestro trabajo, en lo forense, tampoco se puede permitir que otro forense realice valoraciones odontológicas o emita conceptos periciales para lo cual no tiene la competencia.

Por otro lado, el odontólogo clínico y forense ha sido siempre uno de los pioneros en tener que reinventarse, nos hemos visto en la necesidad de transformar el modo de atención al enfrentar las diferentes probabilidades de contaminación transmitidas por la cavidad oral, un ejemplo de ello fue el SIDA, el H1N1 y otras enfermedades transmisibles que se han venido presentado. Es importante resaltar que los odontólogos han implementado protocolos estrictos de bioseguridad, que se siguen muy juiciosamente y éstos se quedarán con nosotros para siempre, haciendo que al incrementar las condiciones de bioseguridad se aumenten los costos de la prestación del servicio y eso ¿quién lo asume? ¿el paciente? ¿el odontólogo? ¿el gobierno? Durante la cuarentena también se han visto afectados económicamente todos aquellos que están involucrados en la cadena de atención odontológica como los auxiliares de odontología, los laboratoristas, proveedores, quienes tampoco han sido tenidos en cuenta para las ayudas gubernamentales.

En conclusión, consideramos que estos son los aspectos que más han afectado a la profesión odontológica durante esta pandemia: la paupérrima unión gremial, la parte económica, la salud física y mental del odontólogo y de su equipo de trabajo y, especialmente el derecho del paciente a acudir al odontólogo por su salud dental que, aunque no corra riesgo de muerte, en algunos casos podría serlo y en otros su salud oral influye de manera importante en su calidad de vida. Somos importantes e irremplazables, este es otro legado que nos deja la pandemia, pero siempre enmarcados en el contexto general del bienestar de salud de la población. Por ello, invitamos a todos los colegas de Latinoamérica a trabajar por el posicionamiento del odontólogo clínico y forense. Debemos unirnos porque ello beneficia no solo al profesional odontólogo, sino también a todos nuestros pacientes que necesitan acudir a la consulta clínica y a las personas que acuden por alguna situación jurídica a los servicios odontológicos forenses, no permitamos que nos reemplacen, nuestra labor es vital.

\section{Referencias bibliográficas}

1. El congreso de Colombia/Capítulo IV De las relaciones de la Odontología con sus colegas/Ley 35 de 1989 Código de Ética del Odontólogo Colombiano/p. 6-7.

2. Andrés Oppenheimer/El futuro del trabajo en la era de la automización/Bogotá D.C., Colombia/Penguim Random House Grupo Editorial, S.A.S./2018. 